\title{
ANALISIS IMPLEMENTASI VISUAL STORYTELLING MARKETING DAN BRAND TRUST SERTA PENGARUH TERHADAP MINAT BELI KOSMETIK WARDAH PADA MAHASISWA DI PURWAKARTA
}

\author{
Oleh : \\ Ade Nurhayati Kusuma Dewi \\ Program Studi Manajemen - STIE DR KHEZ Muttaqien \\ Email : adenurhayatikd@gmail.com \\ Intan Hastikasari Herman \\ Program Studi Manajemen - STIE DR KHEZ Muttaqien
}

\begin{tabular}{l}
\hline Article Info \\
\hline Article History: \\
Received 28 August - 2021 \\
Accepted 02 Sept - 2021 \\
Available Online 25 Sept - \\
2021
\end{tabular}

Keyword:

Purchase intention, visual

storytelling marketing and

brand trust

\section{PENDAHULUAN}

Kesadaran wanita untuk merawat diri dan menjaga penampilan saat ini sangatlah tinggi, maka tak heran jika saat ini banyak sekali merek merek dari mulai skin care, body care serta make up bermunculan. Para pelaku di industri kosmetik menangkap bahwa ini merupakan peluang dan memanfaatkan tren ini sebagai peluang untuk mengembangkan usahanya.

Kementrian Perindustrian menyatakan di tahun 2018 mencatat perkembangan industri kosmetik nasional mengalami kenaikan pertumbuhan sebesar $20 \%$ atau empat kali lipat dari pertumbuhan ekonomi nasional tahun 2007 (dikutip dari mediaindonesia.com) peningkatan ini seiring dengan tren kosmetik yang semakin meningkat dan kosmetik dianggap sebagai kebutuhan primer bagi kaum wanita, yang mana merupakan target utama dari industri kosmetik.

ZAP klinik dan MarkPlus Inc melakukan survey terhadap 17.889 perempuan Indonesia (dikutip dari marketeers.com) hasil survei menunjukkan bahwa merek Asing masih menjadi merek favorit perempuan Indonesia, merek SK II menguasai sebesar 8,90\% sebagai skincare yang paling sering digunakan oleh perempuan di Indonesia. Laneige 
merek dari negara Korea Selatan berada diurutan kedua sebagai skincare terlaris di Indonesia sebesar $7,70 \%$, lalu diurutan ketiga merek The Body Shop asal Brazil yang menguasai pasar kosmetik di Indonesia sebesar 5,50\%.

Merek dari negara Korea Selatan masih menjadi merek favorit perempuan Indonesia, Innisfree menguasai sebesar $4,60 \%$ sedangkan Nature Republic menguasai sebesar 4,20\%. Terakhir merek asal Indonesia yaitu Wardah hanya menguasai sebesar $4,10 \%$ pasar kosmetik di Indonesia. Kondisi ini menunjukkan persaingan di dunia kosmetik sangatlah ketat dan minat beli konsumen pada kosmetik lokal begitu rendah.

Dari survei tersebut, dapat disimpulkan bahwa minat beli konsumen di Indonesia terhadap merek lokal masih sangatlah rendah. Khususnya kosmetik Wardah, Wardah merupakan kosmetik asal Indonesia yang memiliki banyak varian, halal, berkualitas serta memiliki harga yang terjangkau. Tetapi, dikarenakan banyaknya merek yang beredar menyebabkan minat beli pada konsumen Wardah rendah, dapat dilihat dari data penjualan Wardah Periode Desember 2019 - April 2020 :

\section{Grafik 1}

\section{Grafik Penjualan Kosmetik Wardah di Purwakarta Periode Desember 2019 - April 2020}

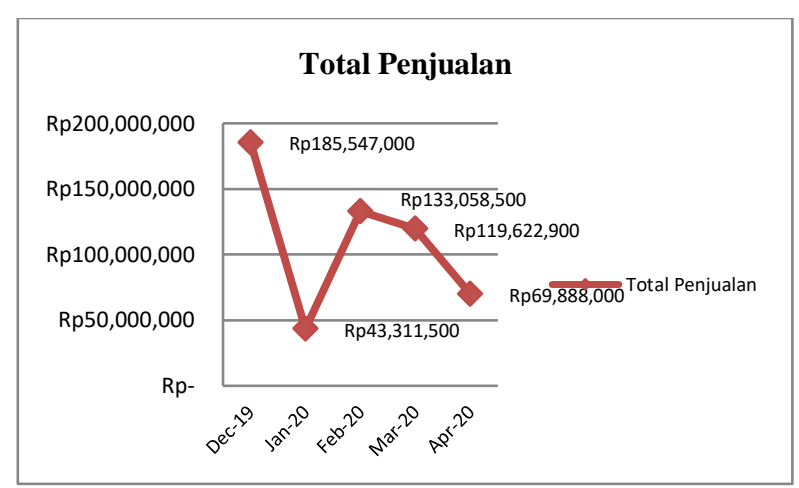

\section{Sumber : Data Penjualan Manager Area \\ Cabang Purwakarta (2019 - 2020)}

Dapat dilihat dari grafik tersebut, penjualan kosmetik Wardah periode Desember 2019 - April 2020 cenderung fluktuatif. Namun pada tiga bulan terakhir menunjukkan penurunan total penjualan. Di bulan Desember penjualan kosmetik sebesar Rp. 185.547.000, namun terjadi penurunan pada bulan Januari menjadi Rp. 43.311.500. Di bulan Februari menunjukkan kenaikan penjualan sebesar Rp. 133.058.500, tetapi dua bulan selanjutnya menunjukkan penurunan penjualan kembali di bulan Maret Rp. 119.622.900 dan yang paling signifikan penurunan terjadi di bulan April menjadi Rp. 69.888.000.
Kondisi ini menunjukkan bahwa minat konsumen untuk membeli kosmetik Wardah menurun. Untuk melihat minat beli pada kosmetik Wardah peneliti melakukan pra - survei yang dilakukan terhadap 30 mahasiswi di Purwakarta, karena mayoritas pengguna kosmetik yaitu wanita.

Kompetisi di pasar kecantikan begitu kompetitif, pelaku usaha di industri kosmetik dituntut agar melakukan berbagai strategi pemasaran yang efektif agar minat beli pada kosmetik Wardah semakin meningkat. Salah satunya dengan memanfaatkan promosi di platform media sosial dengan efektif. Karena di era moderen ini manusia dikehidupan sehari - harinya tidak terlepas dari internet dan smartphone, dapat dilihat data pengguna telepon, internet, media sosial Indonesia menurut Wearesocial Hootsuite yang dirilis pada Januari 2019, sebagai berikut :

\section{Gambar 1}

Data Pengguna Telepon, Internet, Media Sosial Indonesia Menurut Wearesocial (2019)

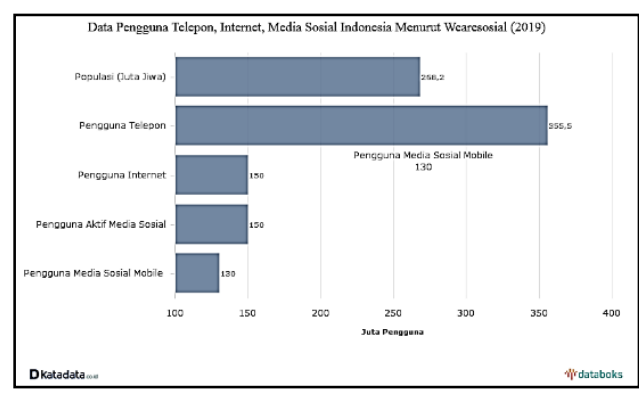

Sumber:

https://databoks.katadata.co.id/datapublish/2019/0 $2 / 08 /$

Saat ini iklan saja tidak cukup untuk menarik konsumen, perusahaan harus mencari cara lain agar maksud dan tujuannya sampai ke konsumen, salah satunya dengan cerita melalui web series ini, karena cerita memiliki kemampuan untuk menyentuh hati dan emosi seseorang selain itu cerita juga mampu menggerakan orang untuk melakukan sesuatu.

Dengan adanya storytelling atau cerita, para penonton atau calon konsumen tidak hanya menikmati certia saja tetapi bisa juga tertarik untuk melakukan transaksi. Kaufman (2003:11) mengatakan bahwa penelitian telah menemukan bahwa storytelling jauh lebih meyakinkan untuk audiens daripada argumen rasional, statistik, atau fakta.

Untuk menjaga agar minat beli konsumen terhadap kosmetik Wardah dan meningkatkan minat beli kosumen, maka pelaku usaha perlu memperhatikan aspek lain yang mempengaruhi minat beli konsumen. Karena menurut Kotler dalam Arista dan Astuti (2011) faktor yang membentuk minat beli konsumen yaitu sikap 
orang lain dan faktor situasi yang tidak terantisipasi.

Maksud dari faktor situasi yang tidak terantisipasi yaitu faktor yang dapat mengubah pendirian konsumen dalam melakukan pembelian. Hal tersebut tergantung dari pemikiran konsumen sendiri, apakah dia percaya diri dalam memutuskan akan membeli suatu barang atau tidak. Maka dari itu pelaku usaha mestinya membentuk kepercayaan merek yang kuat bagi konsumen, agar konsumen selalu dapat mengandalkan mengandalkan kemampuan merek sesuai dengan fungsi yang telah diperlihatkan oleh merek tersebut.

Penelitian terdahulu menjelaskan bahwa adanya hubungan antara brand trust dan minat beli, diperkuat dengan penelitian yang dilakukan oleh Dadang Suhardi, Rika Irmayanti (2019) dengan judul Pengaruh Celebrity Endorser, Citra Merek, dan Kepercayaan Merek Terhadap Minat Beli Konsumen dengan hasil variabel brand trust berpengaruh positif terhadap minat beli.

Penelitian terdahulu yang dilakukan oleh Lee-Yun Pan, Kuan Hung Chen (2019) dengan judul A Study on the Effect of Storytelling Marketing on Brand Image, Perceived Quality, and Purchase Intention in Ecotourism menunjukkan hasil storytelling berpengaruh signifikan terhadap minat beli.

\section{KAJIAN PUSTAKA PEGEMBANGAN HIPOTESIS Visual Storytelling Marketing}

Menurut Google Trends, salah satu istilah pencarian yang tumbuh paling cepat di ruang pemasaran adalah sesuatu yang disebut pemasaran konten (content marketing). Pemasaran konten adalah gagasan bahwa semua merek, untuk menarik dan mempertahankan pelanggan, perlu berpikir dan bertindak seperti perusahaan media.

Storytelling merupakan salah satunya (Pulizzi, 2012:116). Berlawanan dengan iklan, yang umumnya ditransmisikan di sekitar konten orang lain, pemasaran konten adalah pembuatan konten yang bernilai, relevan, dan menarik oleh merek itu sendiri secara konsisten, yang digunakan untuk menghasilkan perilaku positif dari pelanggan atau prospek merek.

Walter dan Gioglio (2014) mendefinisikan visual storytelling sebagai penggunaan gambar, vidio, infografis, presentasi, dan visual lainnya pada platform media sosial untuk membuat cerita grafis seputar nilai-nilai dan penawaran merek utama, selain itu visual storytelling juga diartikan sebagai pertemuan seni dan sains, menyeimbangkan pesan yang dimaksudkan dengan tujuan dan nilai timbal balik sambil berinvestasi dalam medium dan budaya yang mendefinisikannya.

Ini tidak hanya dimaksudkan untuk dikonsumsi tetapi juga dirancang untuk dibagikan, mendidik, memberi informasi, dan menghibur sepanjang jalan.

\section{Dimensi Visual Storytelling Marketing}

\section{1) Design}

"Embrace Visual Imagery" ketika datang ke elemen desain pemasaran visual, menginspirasi bagaimana perusahaan membuat gambar yang menakjubkan dengan bantuan seniman dan fotografer berbakat. Gambar dapat menceritakan kisah dan menambah merek keseluruhan, tanpa menggunakan teks, segala hal dapat mudah disampaikan melalui gambar. contohnya gaya gambar (style), warna gambar (tone), atau tokoh (character) pada cerita.

\section{2) Personalization}

Tema kunci lain dari pemasaran visual adalah personalisasi konten berdasarkan platform. Lewatlah sudah hari-hari ketika tidak masalah untuk menyemprotkan konten yang sama di berbagai platform. Sebaliknya, para pemimpin media sosial merangkul fitur-fitur khusus dan kemampuan masing-masing platform untuk menumbuhkan berbagai jenis engagement dan storytelling.

3) Usefulness

Dengan memainkan kekuatan dari setiap platform media sosial, perusahaan mengambil langkah pertama dalam memastikan bahwa konten visual mereka juga bermanfaat. Namun, personalisasi saja tidak selalu membuat konten bermanfaat. Mendengarkan sosial dapat membantu perusahaan menjadi lebih berguna dan relevan dengan mengungkap tema-tema kunci dan tren di sekitar mana untuk membuat konten visual. Mendengarkan sosial juga dapat membantu perusahaan untuk lebih memahami apa yang mendorong konsumen dan mendorong tindakan, apakah itu sharing, engaging, atau purchasing.

\section{4) Personality}

Selain bermanfaat, pemasaran visual berkinerja lebih baik ketika konten memiliki elemen manusia. Menjadi manusia berarti merasa lebih seperti teman daripada entitas perusahaan. Seorang teman memiliki kepribadian, menghargai hubungan, berbagi pengalaman, dan memahami kapan harus mendengarkan, kapan harus serius, dan kapan harus bersenang-senang. Menjadi manusia berarti tidak memimpin dengan "beli ini sekarang." Alih-alih langsung menjual di situs media sosial, perusahaan perlu memikirkan 
bagaimana orang mendiskusikan dan merekomendasikan produk atau layanan kepada teman (share-experience) dan bagaimana produk atau jasa tersebut harus mudah untuk di mengerti (easy to understand).

\section{5) Storytelling}

Semua contoh pemasaran visual sejauh ini membuktikan bahwa strategi pemasaran visual yang sukses mensyaratkan bahwa elemen bercerita konten sama pentingnya dengan penggunaan visual. Cerita dapat datang dari sejumlah tempat, apakah itu nilai perusahaan, bagaimana orang menikmati produk atau layanan Anda, tonggak utama, atau hanya dengan menjadi tepat waktu dan relevan.

\section{6) Shareworthiness}

Shareworthiness ialah memproduksi konten yang patut untuk dibagikan. Publik bukan hanya sekedar penonton tetapi juga storyteller. Mereka mampu membagikan cerita kita kepada orang lain (share story to others) dan ikut terlibat dalam cerita yang kita ciptakan (share experiences for the brand).

\section{7) Real-time amplification}

Real-timeamplification yaitu penekanan pada konten secara real-time yang mampu membuka peluang untuk interaksi dan engagement secara real-time.

\section{Brand Trust}

Kepercayaan merek menurut (Chaudhuri dan Holbrook, 2001 dalam Rahman, 2020) didefinisikan sebagai kemauan dari rata-rata konsumen untuk bergantung kepada kemampuan dari sebuah merek dalam melaksanakan segala kegunaan atau fungsinya.

Kepercayaan merupakan suatu rasa percaya yang timbul di benak konsumen bahwa ia dapat mengandalkan penjual untuk memberikan layanan yang menjanjikan. Sedangkan brand trust sendiri menurut (Laksono dan Suryadi, 2020) merupakan kesediaan konsumen dalam mengandalkan kemampuan merek sesuai dengan fingsi yang telah diperlihatkan oleh merek tersebut.

Definisi lain kepercayaan merek dari (Delgado, 2014 dalam Laksono dan Suryadi, 2020) yaitu untuk dipercaya dan bersumber pada keyakinan konsumen bahwa produk tersebut mampu memenuhi nilai yang dijanjikan dan intensi baik merek.

Menurut Sangadji dan Sopiah (2013) mengatakan bahwa kepercayaan merek, evaluasi merek, dan maksud untuk membeli merupakan tiga komponen sikap. Kepercayaan merek merupakan komponen kognitif dari sikap, evaluasi merek merupakan komponen afektif atau perasaan, maksud untuk membeli merupakan komponen konatif atau tindakan.

\section{Dimensi Brand Trust}

1) Dimension of Viability (Validity Process)

Mengacu pada persepsi bahwa suatu merek dapat memenuhi atau memuaskan kebutuhan dan nilai-nilai konsumen. Hal ini diukur dengan indikator kepuasan dan nilai.

2) Dimension of Intentionality (Disparity)

Mencerminkan keamanan emosional dalam diri seseorang. Ini mewakili aspek kepercayaan yang melaluinya bukti-bukti yang ada dapat menjamin perasaan aman dalam diri individu. Hal ini diukur dengan keamanan dan kepercayaan.

\section{Minat Beli}

Dalam memasarkan produk, seseorang pemasar perlu memahami konsumen. Mengetahui apa yang dibutuhkannya, apa seleranya, dan bagaimana ia mengambil keputusan (Suwarman, 2002:24 dalam Munir dan Nurjahati, 2019).

Sebelum melakukan keputusan pembelian, konsumen terlebih dahulu akan memunculkan minat beli, minat beli merupakan keinginan terpendam yang ada dalam diri seorang konsumen dan tidak ada seorang pun yang tahu apa yang sebenarnya ada dibenak konsumen.

Definisi dari minat beli sendiri merupakan sebuah pengambilan keputusan untuk membeli suatu merek diantara berbagai merek lainnya (Siahaan:2008 dalam Andi, Suyono, Putra, Hendri:2020).

Menurut Amaliah, Jusni, Munir (2020) minat beli konsumen adalah niat yang timbul dari dalam diri seseorang untuk melakukan pembelian suatu produk atau layanan dengan pertimbangan sebelum proses pembelian berlangsung.

Pendapat lain menurut Kotler dan Keller (2016) dalam Mokhtar (2020) minat beli adalah perilaku yang muncul sebagai respon terhadap objek yang menunjukan keinginan pelanggan untuk melakukan pembelian. Sedangkan menurut pendapat Sciffman dan Kanuk (2015:228) dalam Solihin (2020) minat beli adalah suatu model sikap seseorang terhadap objek barang yang sangat cocok dalam mengukur sikap terhadap golongan produk, jasa, atau merek tertentu.

\section{Dimensi Minat Beli Konsumen}

Menurut Ferdinan : 2002 (dalam Saidani dan Arifin 2012) minat beli dapat diidentifikasikan melalui empat elemen sebagai berikut:

\section{1) Minat Transaksional}

Minat transaksional merupakan kecenderungan seseorang untuk selalu membeli ulang sebuah produk.

\section{2) Minat Referensial}

Minat referensial merupakan kecenderungan seseorang untuk mereferensikan produk yang sudah dibelinya agar dibeli juga oleh orang 
lain, dengan referensi pengalaman konsumsinya.

\section{3) Minat Preferensial}

Minat preferensial merupakan minat yang menggambarkan perilaku seseorang yang selalu memiliki preferensi utama pada produk yang sudah dikonsumsi. Preferensi ini hanya dapat diganti bila terjadi sesuatu dengan produk referensinya.

4) Minat Eksploratif

Minat eksploratif menggambarkan perilaku seseorang yang selalu mencari informasi menganai produk yang diminatinya dan mencari informasi untuk mendukung sifat sifat positif dari produk yang dilangganinya.

\section{Hipotesis}

1. H1 : Diduga visual storytelling marketing berpengaruh terhadap minat beli.

2. H2 : Diduga brand trust berpengaruh terhadap minat beli.

3. H3 : Diduga visual storytelling marketing dan brand trust berpengaruh terhadap minat beli

\section{METODE PENELITIAN}

Metode yang digunakan dalam penelitian ini adalah menggunakan metode deskriptif kuantitatif (kausalitas). Metode deskriptif adalah suatu metode dalam meneliti status sekelompok manusia, suatu objek, suatu set kondisi, suatu sistem pemikiran, ataupun suatu kelas peristiwa pada masa sekarang.

Tabel 3.1

Operasional Variabel

\begin{tabular}{|c|c|c|}
\hline $\mathrm{M}$ & Dimensi & Indikator \\
\hline \multirow{15}{*}{$\begin{array}{l}\text { Visual } \\
\text { Storytelling } \\
\text { Marketing } \\
\text { (X1) }\end{array}$} & \multirow[t]{3}{*}{ Design } & Style \\
\hline & & Tone \\
\hline & & Character \\
\hline & \multirow[t]{2}{*}{ Personality } & Share-experience \\
\hline & & Easy to understand \\
\hline & \multirow[t]{3}{*}{ Usefulness } & Sharing \\
\hline & & Engaging \\
\hline & & Purchasing \\
\hline & \multirow[t]{2}{*}{ Storytelling } & Brand product or services \\
\hline & & Relevancy \\
\hline & \multirow[t]{2}{*}{ Shareworthiness } & Share story to others \\
\hline & & $\begin{array}{l}\text { Share experiences for the } \\
\text { brand }\end{array}$ \\
\hline & \multirow{2}{*}{$\begin{array}{l}\text { Real- } \\
\text { timeamplification }\end{array}$} & Interaction \\
\hline & & Engagement \\
\hline & Personalization & Platform \\
\hline \multirow{4}{*}{$\begin{array}{l}\text { Brand Trust } \\
\text { (X2) }\end{array}$} & \multirow{2}{*}{$\begin{array}{l}\text { Dimension } \\
\text { Viability }\end{array}$} & Kepuasan \\
\hline & & Nilai \\
\hline & \multirow{2}{*}{$\begin{array}{l}\text { Dimension } \\
\text { Intentionality }\end{array}$} & Keamanan \\
\hline & & Kepercayaan \\
\hline $\begin{array}{l}\text { Minat Beli } \\
(\mathrm{Y})\end{array}$ & Minat Transaksional & $\begin{array}{l}\text { Keinginan konsumen untuk } \\
\text { membeli kosmetik wardah. }\end{array}$ \\
\hline
\end{tabular}

\begin{tabular}{|l|l|l|}
\hline & Minat Referensial & $\begin{array}{l}\text { Keinginan konsumen untuk } \\
\text { mereferensikan kosmetik } \\
\text { wardah pada konsumen lain. }\end{array}$ \\
\cline { 2 - 3 } & Minat Preferensial & $\begin{array}{l}\text { Konsumen mengutamakan } \\
\text { kosmetik wardah dalam } \\
\text { memenuhi kebutuhan } \\
\text { kosmetiknya. selalu ingin }\end{array}$ \\
\cline { 2 - 3 } & Minat Eksploratif & $\begin{array}{l}\text { Konsumen tentang } \\
\text { mencari informasi tal } \\
\text { kosmetik wardah. }\end{array}$ \\
\hline
\end{tabular}

Sumber : Diolah peneliti, 2020

Dalam penelitian ini populasi berjumlah 6243 yang berasal dari 7 sekolah tinggi di Purwakarta yaitu Sekolah Tinggi Ilmu Ekonomi DR. Khez Muttaqien, Sekolah Tinggi Ilmu Ekonomi WIKARA, Sekolah Tinggi Ilmu Ekonomi Dan Bisnis Perdana Mandiri, Sekolah Tinggi Ilmu Ekonomi Syariah Darul Ulum Purwakarta, Sekolah Tinggi Agama Islam DR. Khez Muttaqien, Sekolah Tinggi Agama Islam Almuhajirin, Sekolah Tinggi Keguruan Ilmu Pendidikan Purwakarta.

Tabel 3.2

Mahasiswa Sekolah Tinggi Di Kabupaten Purwakarta

\begin{tabular}{|l|c|}
\hline \multicolumn{1}{|c|}{ Nama Sekolah Tinggi } & $\begin{array}{c}\text { Jumlah } \\
\text { Mahasiswa }\end{array}$ \\
\hline $\begin{array}{l}\text { Sekolah Tinggi Ilmu Ekonomi } \\
\text { DR. Khez Muttaqien }\end{array}$ & 1498 \\
\hline $\begin{array}{l}\text { Sekolah Tinggi Ilmu Ekonomi } \\
\text { WIKARA }\end{array}$ & 464 \\
\hline $\begin{array}{l}\text { Sekolah Tinggi Ilmu Ekonomi } \\
\text { Dan Bisnis Perdana Mandiri }\end{array}$ & 1889 \\
\hline $\begin{array}{l}\text { Sekolah Tinggi Ilmu Ekonomi } \\
\text { Syariah Darul Ulum Purwakarta }\end{array}$ & 287 \\
\hline $\begin{array}{l}\text { Sekolah Tinggi Agama Islam } \\
\text { DR. Khez Muttaqien }\end{array}$ & 972 \\
\hline $\begin{array}{l}\text { Sekolah Tinggi Agama Islam } \\
\text { Almuhajirin }\end{array}$ & 865 \\
\hline $\begin{array}{l}\text { Sekolah Tinggi Keguruan Ilmu } \\
\text { Pendidikan Purwakarta }\end{array}$ & 268 \\
\hline Total Mahasiswa & $\mathbf{6 2 4 3}$ \\
\hline
\end{tabular}

Sumber : PDDIKTI (Pangkalan Data Pendidikan Tinggi)

Teknik sampling yang digunakan dalam penelitian ini adalah probability sampling, menurut Sugiono (2016:218) probability sampling adalah teknik pengambilan sampel yang memberikan peluang sama bagi setiap unsur (anggota) populasi untuk menjadi anggota sampel. Jenis teknik yang dipilih untuk penelitian ini adalah cluster sampling, dikarenakan didalam penelitian ini bertujuan untuk meneliti mahasiswa di Purwakarta. Cluster sampling menurut Nazir (2014:273) adalah teknik memilih sebuah sampel dari kelompok - kelompok unit - unit kecil atau cluster, populasi dari cluster merupakan subpopulasi dari total populasi. 
Dari hasil perhitungan dengan rumus slovin diatas maka didapat hasil 98,4 yang dibulatkan menjadi 98 sampel. Berikut pembagian jumlah sampel masing - masing perguruan tinggi di Purwakarta :

Tabel 3.3

Pembagian Jumlah Sampel

\begin{tabular}{|l|c|c|}
\hline \multicolumn{1}{|c|}{ Nama Sekolah Tinggi } & $\begin{array}{c}\text { Jumlah } \\
\text { Mahasiswa }\end{array}$ & $\begin{array}{c}\text { Total } \\
\text { Sampel }\end{array}$ \\
\hline $\begin{array}{l}\text { Sekolah Tinggi Ilmu } \\
\text { Ekonomi DR. Khez } \\
\text { Muttaqien }\end{array}$ & 1498 & 24 \\
\hline $\begin{array}{l}\text { Sekolah Tinggi Ilmu } \\
\text { Ekonomi WIKARA }\end{array}$ & 464 & 8 \\
\hline $\begin{array}{l}\text { Sekolah Tinggi Ilmu } \\
\text { Ekonomi Dan Bisnis } \\
\text { Perdana Mentri }\end{array}$ & 1889 & 29 \\
\hline $\begin{array}{l}\text { Sekolah Tinggi Ilmu } \\
\text { Ekonomi Syariah Darul } \\
\text { Ulum Purwakarta }\end{array}$ & 287 & 4 \\
\hline $\begin{array}{l}\text { Sekolah Tinggi Agama } \\
\text { Islam DR. Khez } \\
\text { Muttaqien }\end{array}$ & 872 & 14 \\
\hline $\begin{array}{l}\text { Sekolah Tinggi Agama } \\
\text { Islam Almuhajirin }\end{array}$ & 268 & 4 \\
\hline $\begin{array}{l}\text { Sekolah Tinggi Keguruan } \\
\text { Ilmu Pendidikan } \\
\text { Purwakarta }\end{array}$ & 985 \\
\hline \multicolumn{1}{|c|}{ Total Keseluruhan Sampel } \\
\hline
\end{tabular}

Sumber : Diolah Peneliti (2020)

\section{HASIL DAN PEMBAHASAN}

Hasil Penelitian

Dari kuesioner variabel visual storytelling marketing, dapat diketahui bahwa hasil tanggapan responden memiliki index variabel sebesar 3,145. Sesuai dengan tabel skor pada tabel 4.4 index dari variabel X1 ini dapat diartikan bahwa semua responden memberikan persepsi "Cukup" terhadap variabel visual storytelling marketing.

Jumlah item tertinggi dari variabel visual storytelling marketing adalah sebesar 3,58 dengan pernyataan "Saya merasa pengambilan gambar dalam web series "Gratefulato : Selalu bersyukur" mampu menampilkan produk dari kosmetik Wardah dengan baik" hal ini menandakan bahwa web series tersebut mampu menampilkan produknya dengan baik.

Sedangkan jumlah terendah dari item variabel visual storytelling marketing adalah "Saya akan membagikan web series "Gratefulato : Selalu bersyukur" kepada kerabat disekitar saya" dengan skor 3,18 . Hal ini menandakan bahwa web series belum mampu menciptakan minat penonton untuk mereferensikan web series tersebut kepada yang lainnya.
Perlunya peningkatan cerita dan aspek lainnya agar web series lebih menarik, sehingga selain menonton untuk dirinya sendiri para penonton juga tertarik untuk membagikan web series tersebut kepada yang lainnya.

Dari hasil kuesioner brand trust menunjukkan index variabel sebesar 3,055, sesuai dengan tabel skor pada tabel 4.4 index dari variabel X2 ini dapat diartikan bahwa semua responden memberikan persepsi "Cukup" terhadap variabel brand trust.

Jumlah item tertinggi dari dimensi brand trust yaitu item dengan pernyataan "Saya percaya untuk menggunakan kosmetik dari merek Wardah"dengan jumlah 3,23. Dapat diambil kesimpulan bahwa merek kosmetik Wardah sudah berhasil menciptakan kepercayaan pada mereknya. Sedangkan item terendah dari variabel brand trust yaitu "Saya percaya reputasi kosmetik Wardah baik karena sudah terdaftar BPOM dan berlabel halal" dengan jumlah 2,9. Dapat disimpulkan bahwa masih banyak konsumen yang belum mempercayai produk dari kosmetik Wardah belum terdaftar di BPOM dan Halal, dalam hal ini merek kosmetik Wardah harus melakukan sosialisasi lebih mendalam mengenai pengenalan produk kepada kosumen bahwa semua produk dari kosmetik sudah terdaftar BPOM dan Halal.

Dari hasil kuesioner variabel minat beli menunjukkan index variabel sebesar 4,325 . Sesuai dengan tabel skor pada tabel 4.4 index dari variabel $\mathrm{Y}$ ini dapat diartikan bahwa semua responden memberikan persepsi "Sangat Baik" terhadap variabel minat beli.

Jumlah item tertinggi pada variabel minat beli yaitu sebesar 7,69 dengan pernyataan "Saya akan merekomendasikan kosmetik Wardah kepada keluarga dan kerabat terdekat". Hal ini membuktikan bahwa merek dari kosmetik Wardah memiliki reputasi dan kualitas yang baik, karena mampu mencipakan minat referensi konsumennya.

Sedangkan jumlah terendah pada variabel minat beli yaitu hanya sebesar 3,09 dengan pernyataan "Saya akan mencari tahu lebih banyak informasi mengenai kelebihan dan kekurangan kosmetik Wardah".

Dapat diambil kesimpulan bahwa minat eksporatif konsumen kosmetik Wardah masih rendah, dalam hal ini merek dari kosmetik Wardah harus membuat produknya lebih bervariasi dan mengiklankan produknya lebih menarik, agar konsumen tertarik untuk mencari tau lebih banyak mengenai kosmetik Wardah.

Berdasarkan pada hasil perhitungan SPSS, maka dapat diperoleh persamaan regresi linear berganda sebagai berikut:

$Y=1,675+0,093_{(\mathrm{X} 1)}+0,492_{(\mathrm{X} 2)}+$ Error term 
Merujuk dari hasil persamaan regresi linear berganda di atas, maka dapat diinterprestasikan sebagai berikut:

1) Diperoleh nilai konstanta ( $\beta$ o) sebesar 1,675. Nilai bermakna bahwa jika variabel terikat (minat beli) tidak dipengaruhi oleh kedua variabel bebas(visual storytelling marketing dan brand trust), maka besarnya minat beli kosmetik Wardah yaitu bernilai 1,675.

2) Nilai koefisien regresi $\left(\beta_{1}\right)$ pada variabel bebas (visual storytelling marketing) bernilai positif yang menunjukan adanya hubungan yang searah antara variabel ini dengan variabel terikat (minat beli). Koefisien regresi variabel minat beli sebesar $\mathbf{0 , 0 9 3}$ bermakna bahwa visual storytelling marketing mempunyai pengaruh terhadap minat beli sebesar 0,093 . Dapat dikatakan setiap peningkatan 1 visual storytelling marketing (dengan asumsi variabel tersebut tidak berubah) maka akan meningkatkan minat beli kosmetik Wardah pada mahasiswi di Purwakarta sebesar 1,768.

3) Nilai koefisien regresi $\left(\beta_{2}\right)$ variabel bebas (brand trust) bernilai positif yang menunjukan adanya hubungan yang searah antara variabel ini dengan variabel terikat (minat beli). Koefisien regresi variabel brand trust sebesar 0,492 bermakna bahwa setiap brand trust konsumen mempunyai pengaruh terhadap minat beli sebesar 0,492. Dapat dikatakan setiap peningkatan 1 unit brand trust konsumen (dengan asumsi variabel tersebut tidak berubah) maka akan meningkatkan minat beli kosmetik Wardah pada mahasiswi di Purwakarta menjadi 2,167.

4) Koefisien regresi variabel $\left(\beta_{1}\right) \mathbf{0 , 0 9 3}$ dan koefisien regresi variabel $\left(\beta_{2}\right) \mathbf{0 , 4 9 2}$. Dapat dikatakan setiap peningkatan masing-masing 1 unit visual storytelling marketing dan brand trust (dengan asumsi kedua variabel tersebut tidak berubah) maka akan meningkatkan minat beli kosmetik Wardah pada mahasiswi di Purwakarta menjadi 2,1763.

Berdasarkan hasil koefisien korelasi yang dihasilkan dari output analisis SPSS dapat diketahui nilai korelasi Pearson antara variabel independen (visual storytelling marketing) terhadap variabel dependen (minat beli) sebesar 0,594 yang mana nilai koefisien korelasi ini berada di antara interval koefisien $\mathbf{0 . 4 0}$ - $\mathbf{0 , 5 9 9}$ yang menyatakan tingkat hubungan positif yang "sedang". Dan koefisien korelasi antara variabel independen (brand trust) terhadap variabel dependen (minat beli) sebesar 0,727. Nilai Koefisien korelasi tersebut berada di antara interval koefisien $\mathbf{0 . 6 0}$ - 0.799 yang menyatakan tingkat hubungan positif yang "kuat".
Berdasarkan hasil pengujian dan analisis SPSS melalui regresi linier berganda, maka pada tabel Model Summary ini dapat diketahui bahwa nilai $\mathrm{R}$ square sebesar $\mathbf{0 , 5 8 1}$. Nilai ini mengandung arti bahwa variabel independen (visual storytelling marketing dan brand trust) secara simultan memberikan pengaruh terhadap variabel dependen (minat beli) kosmetik Wardah pada mahasiswi di Purwakarta sebesar 58,1\%. Kemudian sisanya sebesar 41,9\% dipengaruhi oleh variabel lain yang tidak diteliti.

\section{Pembahasan}

\section{Pengaruh Visual Storytelling Marketing terhadap Minat Beli Kosmetik Wardah pada Mahasiwa di Purwakarta.}

Berdasarkan hasil analisis data secara statistik dapat dibuktikan bahwa visual storytelling marketing memiliki pengaruh positif signifikan terhadap minat beli kosmetik Wardah pada mahasiswi di Purwakarta, hal dilihat dari hasil uji t (uji parsial) diperoleh bahwa untuk nilai t hitung lebih besar dari nilai $\mathrm{t}$ tabel, variabel visual storytelling marketing memiliki nilai sebesar $\mathbf{3 , 4 7 3}$ sedangkan nilai t tabel adalah 1,6610 atau 3,473> 1,6610 .

Kemudian terlihat pula bahwa nilai sig hitung lebih kecil dari nilai sig standar 0.05 atau $\mathbf{0 , 0 0 1}<\mathbf{0 . 0 5}$ maka $\mathrm{H}_{0}$ ditolak dan Ha diterima. Jadi dapat disimpulkan bahwa visual storytelling marketing memiliki pengaruh postitif signifikan terhadap minat beli kosmetik Wardah pada mahasiwa di Purwakarta.

Hal ini sejalan dengan penelitian yang dilakukan oleh Lee-Yun Pan dan Kuan Hung Chen (2019) storytelling marketing berpengaruh secara positif pada minat beli.

Pengaruh Brand Trust terhadap Minat Beli Kosmetik Wardah pada Mahasiwa di Purwakarta.

Berdasarkan hasil analisis data secara statistik dapat dibuktikan bahwa brand trust memiliki pengaruh positif signifikan terhadap minat beli kosmetik Wardah pada mahasiswi di Purwakarta, hal dilihat dari hasil uji t (uji parsial) diperoleh bahwa untuk nilai t hitung lebih besar dari nilai t tabel, variabel brand trust memiliki nilai sebesar 7,188 sedangkan nilai t tabel adalah $\mathbf{1 , 6 6 1 0}$ atau 7,188 $>1,6610$.

Kemudian terlihat pula bahwa nilai sig hitung lebih kecil dari nilai sig standar 0.05 atau $\mathbf{0 , 0 0 0}<\mathbf{0 . 0 5}$ maka $\mathrm{H}_{0}$ ditolak dan Ha diterima. Jadi dapat disimpulkan bahwa brand trust memiliki pengaruh postitif signifikan terhadap minat beli kosmetik Wardah pada mahasiwa di Purwakarta.

Hal ini sejalan dengan penelitian yang dilakukan oleh Dadang Suhardi dan Rika Irmayanti 
(2019) bahwa brand trust berpengaruh secara positif signifikan terhadap minat beli.

Pengaruh Visual Storytelling Marketing dan Brand Trust terhadap Minat Beli kosmetik Wardah pada Mahasiswi di Purwakarta

Berdasarkan hasil uji f (uji simultan), jelas terbukti bahwa secara simultan variabel independen (visual storytelling marketing dan brand trust) memiliki nilai $\mathrm{F}$ hitung yang lebih besar dari nilai $F$ tabel $(\mathbf{6 5 , 8 9 9}>\mathbf{3 , 0 9})$, serta nilai signifikansi hitungnya lebih kecil dari signifikansi standar $(\mathbf{0 , 0 0 0}<\mathbf{0 , 0 5})$. Dari hasil analisis tersebut, maka dapat disimpulkan bahwa secara simultan variabel independen (visual storytelling marketing dan brand trust) memiliki pengaruh yang signifikan terhadap variabel dependen (minat beli) kosmetik Wardah pada mahasiswi di Purwakarta.

Selanjutnya berdasarkan hasil perhitungan Koefisien Determinasi (R square) dapat diketahui bahwa variabel independen (visual storytelling marketing dan brand trust) dalam penelitian ini mampu memberikan pengaruh secara simultan sebesar 58,1\% terhadap variabel dependen (minat beli).

Maka dapat disimpulkan bahwa kedua variabel independent tersebut sangat jelas secara bersama - sama memiliki kontribusi terhadap minat beli kosmetik Wardah pada mahasiswi di Purwakarta. Seperti yang dikatakan Kaufman (2003) bahwa storytelling jauh lebih meyakinkan untuk audiens daripada argumen rasional, statistik, atau fakta

\section{KESIMPULAN}

Berdasarkan hasil penelitian dan pembahsan yang telah dilakukan sebelumnya dengan bersandar pada masalah yang telah dirumuskan pada bab pendahuluan, maka dapat ditarik kesimpulan seperti berikut :

1. Visual storytelling marketing secara nyata memberikan kontribusi terhadap minat beli konsumen. Artinya jika variabel visual storytelling marketing naik atau meningkat, maka minat beli kosmetik Wardah akan ikut meningkat sebesar t hitung pada variabel visual storytelling marketing. Begitupun sebaliknya jika variabel visual storytelling marketing turun, maka minat beli kosmetik Wardah juga ikut turun.

2. Brand trust secara nyata memberikan kontribusi terhadap minat beli konsumen. Artinya jika variabel brand trust naik atau meningkat, maka minat beli kosmetik Wardah akan ikut meningkat sebesar $t$ hitung pada variabel brand trust. Begitupun sebaliknya jika variabel brand trust turun, maka minat beli kosmetik Wardah juga ikut turun.
3. Secara bersama - sama kedua variabel independen yaitu visual storytelling marketing dan brand trust nerpengaruh secara nyata terhadap minat beli. Sehingga dapat memberikan kontribusi yang besar pada minat beli kosmetik Wardah pada mahasiswa di Purwakata.

\section{REFERENSI}

American Marketing Association (AMA) yang dikutip oleh Philip Kotler dan Keller Kevin Lane.2009. yang diterjemahkan oleh Bob Sabran.

Ariescy, R. R., Amriel, E. E. Y., \& Anindita, R. (2019). Pengaruh Iklan Hijau dan Kesadaran Lingkungan terhadap Minat Beli dan Keputusan Pembelian Air Mineral Merek Ades di Kabupaten Jember. Jurnal MEBIS (Manajemen dan Bisnis), 4(2), 142-149.

Arikunto, Suharsimi. (2014). Prosedur Penelitian Suatu Pendekatan Praktik. Jakarta : Rineka Cipta.

Arista, D., \& Astuti, S. R. T. (2011). Analisis pengaruh iklan, kepercayaan merek, dan citra merek terhadap minat beli konsumen. Jurnal Ilmiah Aset, 13(1), 37-45.

Chaudhuri, A., \& Holbrook, M. B. (2001). The chain of effects from brand trust and brand affect to brand performance: the role of brand loyalty. Journal of marketing, 65(2), 81-93.

Ekaterina Walter dan Jessica Gioglio. (2014). The Power of Visual Storytelling: How to Use Visual, Videos, and Social Media to Market Your Brand. New York: McGrawHill Education.

Kaufman, Barbara. (2003).Stories that SELL, stories that TELL, Journal of Business Strategy, Vol. 24 Iss 2 pp. 11 -15

Kotler, Philip dan Kevin Lane Keller. (2008). Manajemen Pemasaran, Terjemahan : Bob Sabran. Edisi 13 Jilid 1.Erlangga,Jakarta.

Kustini, N. I. (2011). Experiential marketing, emotional branding, and brand trust and their effect on loyalty on honda motorcycle product. Journal of Economics, Business, \& Accountancy Ventura, 14(1).

KUSUMANINGRUM, G., Septi, K. P., \& SE, M. (2020). Pengaruh Celebrity Endorser, Brand Credibility, Brand Trust Terhadap Purchase Intention Pada Produk Wardah yang Dilakukan Melalui Instagram(Doctoral dissertation, IAIN SURAKARTA).

Lau, G.T., Lee, S.H. Consumers'. (1999).Trust in a Brand and the Link to Brand Loyalty. 
Journal of Market-Focused Management 4, 341-370.

Munir, M. S., Nurhajati, N., \& Wahono, B. (2019). PENGARUH BRAND ORIGIN, BRAND AMBASSADOR DAN BRAND IMAGE TERHADAP MINAT BELI PARFUM AXE (Studi Kasus Mahasiswa Fakultas Ekonomi dan Bisnis Jurusan Manajemen Universitas Islam Malang). Jurnal Ilmiah Riset Manajemen, 8(06).

Nazir, Moh. (2014). Metode Penelitian. Bogor: Ghalia Indonesia.

Pravitaswari, N., Arifin, Z., \& Mawardi, M. K. (2018). Pengaruh Storytelling Marketing terhadap Brand Equity dan Keputusan Pembelian (Survei Pada Video Iklan Allure Matcha Latte Story Di Youtube). Jurnal Administrasi Bisnis, 57(1), 30-37.

Pulizzi, J. (2012). The rise of storytelling as the new marketing. Publishing research quarterly, 28(2), 116-123.

Rizan, M., Saidani, B., \& Sari, Y. (2012). Pengaruh Brand Image Dan Brand Trust Terhadap Brand Loyalty Teh Botol Sosro Survei Konsumen Teh Botol Sosro Di Food Court Itc Cempaka Mas, Jakarta Timur. JRMSIJurnal Riset Manajemen Sains Indonesia, 3(1), 1-17.
Saidani, B., \& Arifin, S. (2012). Pengaruh kualitas produk dan kualitas layanan terhadap kepuasan konsumen dan minat beli pada ranch market. JRMSI-Jurnal Riset Manajemen Sains Indonesia, 3(1), 1-22.

Salfina, L., \& Gusri, H. (2018). Pengaruh Citra Merek, Kualitas Produk dan Harga Terhadap Minat Beli Pakaian Anak-anak Studi Kasus Toko Rizky dan Afdal Pariaman. Jurnal Indovisi, l(1).

Sugiyono. (2016). Metode Penelitian Pendekatan Kuantitatif, Kualitatif, dan R \& D. Bandung: Alfabeta.

Suhardi, D., \& Irmayanti, R. (2019). Pengaruh Celebrity Endorser, Citra Merek, dan Kepercayaan Merek Terhadap Minat Beli Konsumen. Jurnal Inspirasi Bisnis dan Manajemen, 3(1), 53-62.

Tetanoe, V. R. (2014). Pengaruh Experiential Marketing Terhadap Pembelian Ulang Dengan Kepuasan Pelanggan Sebagai Variable Intervening di Breadtalk Surabaya Town Square. Jurnal Strategi Pemasaran, 2(1), 1-12.

Vu, T., \& Medina, S. (2014). Storytelling marketing and its impact on developing company brand identity, case company Zara. 